\title{
Patterns of resident health workforce turnover and retention in remote communities of the Northern Territory of Australia, 2013-2015
}

Deborah J Russell ${ }^{1 *}$, Yuejen Zhao ${ }^{2}$, Steven Guthridge ${ }^{2}$, Mark Ramjan², Michael P Jones ${ }^{3}$, John S Humphreys ${ }^{4}$ and John Wakerman ${ }^{5}$

\begin{abstract}
Background: The geographical maldistribution of the health workforce is a persisting global issue linked to inequitable access to health services and poorer health outcomes for rural and remote populations. In the Northern Territory (NT), anecdotal reports suggest that the primary care workforce in remote Aboriginal communities is characterised by high turnover, low stability and high use of temporary staffing; however, there is a lack of reliable information to guide workforce policy improvements. This study quantifies current turnover and retention in remote NT communities and investigates correlations between turnover and retention metrics and health service/community characteristics.
\end{abstract}

Methods: This study used the NT Department of Health 2013-2015 payroll and financial datasets for resident health workforce in 53 remote primary care clinics. Main outcome measures include annual turnover rates, annual stability rates, 12-month survival probabilities and median survival.

Results: At any time point, the clinics had a median of 2.0 nurses, 0.6 Aboriginal health practitioners (AHPs), 2.2 other employees and 0.4 additional agency-employed nurses.

Mean annual turnover rates for nurses and AHPs combined were extremely high, irrespective of whether turnover was defined as no longer working in any remote clinic (66\%) or no longer working at a specific remote clinic (128\%). Stability rates were low, and only $20 \%$ of nurses and AHPs remain working at a specific remote clinic 12 months after commencing. Half left within 4 months.

Nurse and AHP turnover correlated with other workforce measures. However, there was little correlation between most workforce metrics and health service characteristics.

Conclusions: NT Government-funded remote clinics are small, experience very high staff turnover and make considerable use of agency nurses. These staffing patterns, also found in remote settings elsewhere in Australia and globally, not only incur higher direct costs for service provision-and therefore may compromise long-term sustainability-but also are almost certainly contributing to sub-optimal continuity of care, compromised health outcomes and poorer levels of staff safety. To address these deficiencies, it is imperative that investments in implementing, adequately resourcing and evaluating staffing models which stabilise the remote primary care workforce occur as a matter of priority.

Keywords: Remote health, Rural workforce, Health workforce, Fly-in/fly-out, Rural health services, Aboriginal, Aboriginal health practitioner, Remote area nurse, Turnover, Retention

\footnotetext{
* Correspondence: deborah.russell@monash.edu

${ }^{1}$ Monash Rural Health, Monash University, PO Box 666, Bendigo, Victoria

3552, Australia

Full list of author information is available at the end of the article
}

(c) The Author(s). 2017 Open Access This article is distributed under the terms of the Creative Commons Attribution 4.0 International License (http://creativecommons.org/licenses/by/4.0/, which permits unrestricted use, distribution, and reproduction in any medium, provided you give appropriate credit to the original author(s) and the source, provide a link to the Creative Commons license, and indicate if changes were made. The Creative Commons Public Domain Dedication waiver (http://creativecommons.org/publicdomain/zero/1.0/) applies to the data made available in this article, unless otherwise stated. 


\section{Background}

Geographical maldistribution of the health workforce is a persisting global issue that has been linked with the inability of rural and remote populations to gain equitable access to health services and consequent poorer health outcomes [1]. Maldistribution results in absolute and relative shortages of rural primary care workers in many countries, irrespective of the country's wealth [2-7]. In Australia, the 2013 Review of Australian Government Health Workforce Programs found that the most significant primary care workforce issue was the distribution of health workers [8]. Addressing inequities relating to the maldistribution of health workers requires workforce planners to have a good understanding of health worker transitions into and out of rural and remote areas. This, in turn, requires measurement of these transitions and monitoring changes over time, so that the effectiveness of any strategies devised to optimise health worker recruitment, turnover and retention can be developed and assessed.

Recent research suggests that no single workforce metric assessing turnover or retention is sufficient, as each is likely to have considerable limitations if used in isolation [9]. Instead, a suite of measures provides more comprehensive information about both the health workers who are leaving rural and remote communities and, perhaps more importantly, those who are staying $[10,11]$. While the health workforce literature identifies many different indicators of turnover and of retention [12], key metrics relevant to the Australian rural and remote health workforce context include annual turnover rates, stability rates, survival probabilities and median survival [9]. A second component of workforce mobility is the level at which turnover or retention outcomes are determined and reported. This level has been variously defined, for example, retention in a practice, retention in a community, and retention in a larger health organisation [13]. Data from the United States of America indicate annual health service turnover rates for hospital-based nurses of up to $20 \%$ [14, 15]. Other comparative research, also from the USA, suggests that annual hospital staff turnover rates of $4-12 \%$ are low, $12-21 \%$ medium and $22-44 \%$ high [16]. Australian research reports average annual organisational turnover of nurses from the Northern Territory Government (NTG) Department of Health (DoH) of 35\% and organisational turnover of permanent Queensland Health nurses of $20 \%$, with much higher turnover rates and lower stability rates experienced by nurses working in smaller more remote health services $[17,18]$.

Published Northern Territory (NT) reports are now 10 or more years old, and considerable changes have occurred in the ensuing period, particularly with regard to the Australian Government's NT Emergency Response
(NTER) which was initiated in 2007 [19]. While many changes occurred in the targeted NT remote Aboriginal communities as a result of NTER, one key feature impacting on the health workforce in remote communities was the extra financial resources available, leading to increased use of short-term visiting health workers. The Remote Area Health Corps (RAHC), for example, was established in 2008 and received Australian Government funding to recruit metropolitan-based health professionals for periods of service of 3 to 12 weeks [20]. It has been suggested, however, that high levels of shortterm visiting health workers in NT Aboriginal communities causes frustration for experienced permanent staff and may impact negatively on long-term service sustainability, quality of care and, ultimately, health outcomes. However, the extent to which quantitative evidence supports such assertions has not yet been rigorously examined $[21,22]$.

Additionally, in 2002, the Aboriginal and Torres Strait Islander Workforce National Strategic Framework proposed changes affecting the registration requirements, professional recognition and role of Aboriginal health workers (AHWs). In the same year, completion of Certificate 4 competency-based training became a requirement for newly registered AHWs in NT and for existing AHWs with Certificate 3 level qualifications who wished to progress to a higher career level. Numbers of AHWs registered in the NT fluctuated between approximately 250 and 340 between 2004 and 2010, a decline from registrations in excess of 400 in the late twentieth century [23]. In July 2012, national registration for Aboriginal and Torres Strait Islander health practitioners (hereafter referred to, using the NT term, as Aboriginal health practitioners, or AHPs) was introduced, replacing the previous classification of AHWs. In 2012, 2013 and 2014, there were 219, 216 and 201 registered AHPs in the NT respectively, representing a further decline in AHP numbers [24]. How these recent reductions in numbers of AHPs registered in NT have manifested in remote NT Aboriginal communities, in terms of supply, turnover and stability of AHPs employed in a permanent capacity by NTG DoH is not known.

Other gaps in knowledge include current turnover rates, stability rates and survival probabilities for nurses and for AHPs; correlation between key workforce metrics in these remote contexts; and whether there are differences in turnover rates, stability rates and health worker survival patterns amongst the different remote communities and the extent to which differences are related to observable community characteristics such as geographical remoteness, community population size and health service size. Finally, we do not know to what extent use of casual and agency nurse staffing in remote 
communities is associated with turnover and retention of permanent employees and hence with workforce sustainability in remote communities. These are important evidence gaps that limit the ability of workforce planners and policymakers to understand and address suboptimal health service performance related to high turnover and poor retention of health workers in remote communities.

The aims of this paper, therefore, are threefold. Firstly, to describe current (2013-2015) health workforce turnover and retention patterns for nurses and AHPs living and providing clinical services in government health services in remote NT communities. Secondly, to investigate how key workforce metrics correlate with each other. Thirdly, to investigate how key workforce metrics correlate with health service characteristics, including community remoteness and isolation measures, health service population catchment, and health service size.

\section{Methods}

\section{Study setting}

This study is set in the remote NT of Australia, covering an area of approximately 1.3 million $\mathrm{km}^{2}$. The NT is sparsely settled. Of the population of approximately 244,000 people, $27 \%$ identify as Aboriginal. Most (80\%) NT Aboriginal people live in remote towns and communities [25]. During the study period, the NTG DoH provided health care services in 53 remote NT communities, while non-government organisations (Aboriginal Controlled Community Health Organisations) provided health care services in a further 28 remote communities. Primary care delivery in remote NT communities is generally provided by resident Remote Area Nurses and Midwives (hereafter referred to as nurses) and AHPs with professional support provided by telehealth and scheduled intermittent visits from medical and allied health practitioners. Two health services in very small remote communities did not have nurses, and 11 health services did not have AHPs; however, there were no other systematic differences in health service characteristics. Primary care in remote communities was supported by secondary care available in five public NT hospitals. The focus of this study was on the resident clinical staff (nurses and AHPs) in remote NTG-operated health services.

\section{Data}

Two separate data sources were used. The first was the Personnel Information and Payroll Systems (PIPS) data from NTG DoH (3 January 2013 to 30 December 2015). This provides comprehensive, individual-level, de-identified information on all nurses and AHPs paid directly through the NTG DoH payroll in any of the 53 remote clinics. Some nurses recruited through a nurse employment agency are employed on temporary or casual NTG DoH contracts and are captured by the PIPS dataset. Other agency nurses are paid directly by an agency and are therefore not included in PIPS data. These agency-employed nurses, however, are identifiable through labour hire costs in NTG Government Accounting System (GAS). GAS expenditures on agency nurse labour hire costs were used to derive the aggregated full-time equivalent (FTE) agency-employed nurses working in remote health services using the standard NTG DoH formula of agency labour expenses divided by twice the departmental annual average nurse personnel cost [26].

\section{Analysis}

In this study, an exit was primarily defined at a health service level (primary turnover profile), that is, when an employee left one of the 53 specific health clinics for a period of more than 12 weeks.

A secondary definition of an exit, at a remote health level (secondary turnover profile), is also reported, when an employee ceased working in remote health, that is, no longer worked in any of the 53 remote health clinics. In this instance, remote inter-clinic moves were ignored.

Measures of health worker supply were number of unique employees, average annual headcounts, average FTE, and agency-employed nurse FTE ratios, defined as follows:

1. Total number of unique employees (sum of individuals employed in each year)

2. Average annual headcounts (average number of individuals employed in each pay period in each year)

3. Average FTE (average FTE employed in each pay period in each year)

4. Agency-employed nurse FTE ratio

$$
=\frac{\text { average agency employed nurse FTE }}{\text { sum of nurse FTE on organisational chart }}
$$

The key turnover and retention metrics were averaged over 3 years and based on headcounts (except where specified as FTE):

1. The turnover measure was Annual turnover rates (\%)

$$
=\frac{\text { total number of exits in } 12 \text { month period }}{\text { average number of employees in } 12 \text { month period }} \times 100
$$

The retention measures were 
2. Annual stability rates (\%)

$=\frac{\text { Number of employees at start of year who remain employed } 12 \text { months later }}{\text { Number of employees at start of year }} \times 100$

3. Experienced nurses or AHPs

$=\begin{gathered}\text { Number of pay periods per calendar year with at least one nurse or AHP } \\ \text { who has been at that health service for } 2 \text { or more years continuously }\end{gathered}$

4. Survival probability after 12 months (nurses and AHPs)

$=\frac{\text { Number remaining employed beyond } 12 \text { months after commencing at a remote health service }}{\text { Number at risk of exiting a remote health service }}$

5. Median survival time in years (nurses and AHPs)

Time from commencing at a remote health service at which the probability of remaining

employed at the health service equals the probability of having exited which is equal to 0.5

Summary statistics for each of the key metrics were analysed by community population size and whether the communities were predominantly Aboriginal or not. Aboriginal community population size was distributed into four categories $(<200,200-349,350-799$, $\geq 800$ ). Since there were only seven predominantly non-Aboriginal communities, it was not appropriate to stratify non-Aboriginal communities by population size. Community population size estimates were based on 30 June 2012 Australian Bureau of Statistics Estimated Resident Populations. 2011 Australian Bureau of Statistics Census data for Indigenous Locations were used to determine whether a community was predominantly ( $>50 \%)$ Aboriginal or not. 2012 ABS Estimated Resident Population data were very strongly $(r=0.97)$ correlated with 2014 health service records of catchment populations which clinic staff maintain on the number of currently active patients. Distances to the nearest hospital and to Darwin or Alice Springs (whichever was closer) were measured using Google Maps straight line distances in kilometres. The 20152016 NTG DoH Top End Health Service and Central Australia Health Service organisational charts were used to determine the number of FTE nurse and AHP positions at each remote health service. Summary statistics were reported as means with $95 \%$ confidence intervals or medians with interquartile ranges (IQR). Pearson correlations were used with a significance test to explore associations between key workforce metrics and also between key workforce metrics and health service characteristics.

Ethics approval was received from the Human Research Ethics Committee of the NTG DoH and Menzies School of Health Research (2015-2363).

\section{Results}

In total, the number of unique nurses, AHPs and other staff members on the payroll for the 53 clinics in the 3year study period were 470, 93 and 583 respectively. The average annual headcounts for nurses, AHPs and other employees were 272, 67 and 314 respectively. The total FTE for the 53 clinics was 68.7 and 23.8 for nurses and AHPs respectively. In any pay period, the median number of nurses per clinic was 1.97 (IQR 1.38, 3.29), AHPs per clinic was 0.60 (IQR 0.04, 1.27) and other employees per clinic was 2.20 (IQR 0.85, 3.85). The median number of nurse, AHP and other position types shown on 20152016 organisational charts for these remote health services was 2.0 (IQR 2.0, 4.0), 1.0 (IQR 1.0, 4.0), and 2.5 (IQR 1.7, 4.6) respectively.

The median straight line distance to the nearest hospital of these health services was $205 \mathrm{~km}$ (IQR 143, 248), while the median distance to Alice Springs or Darwin was $247 \mathrm{~km}$ (IQR 180, 390). The median population catchment for the health services was 460 (IQR 236, 798). 
Overall, 347 nurse and AHP individuals ceased providing care in any remote health service (secondary turnover profile) during the 2013-2015 period. This was an annual turnover rate of $65.8 \%(95 \% \mathrm{CI} 58.3,74.1)$ for nurses and AHPs combined, with 74.4\% (95\%CI 65.3, 84.7) for nurses and $37.8 \%(95 \% \mathrm{CI} 27.7,51.6)$ for AHPs.

The mean overall annual turnover rate at the clinic level (primary turnover profile) for nurses and AHPs combined was estimated as $128 \%$ (95\% CI 114, 144) (Table 1). Annual stability rates averaged $55.3 \%$ (95\% CI 49.6, 61.6) for nurses and AHPs. The mean probability that nurses and AHPs stay at least 12 months is 0.20 (95\% CI 0.16, 0.24), and within 0.34 (95\% CI $0.27,0.42)$ years of commencement, half the nurses and AHPs have left. Point estimates of the 12-month survival probability and median survival of AHPs were longer than for nurses, although this difference was not statistically significant (Tables 2 and 3). Average annual stability rates, however, were significantly higher for AHPs at $76.3 \%$ (95\% CI 63.5, 91.7) compared with 48.3\% (95\% CI $42.3,55.2)$ for nurses.

Remote NT health services had high levels of agencyemployed nurse use. Of the 51 health services that had nurse positions, agency-employed nurses provided a median of 0.40 FTE per clinic (IQR 0.26, 0.58). On average, for every 1.0 FTE nurse position on organisational charts, there were 0.15 FTE $(95 \%$ CI 0.10, 0.23) agency-employed nurses.

Annual turnover rates for nurses and AHPs combined were significantly correlated with other workforce metrics, though not with agency-employed nurse FTE ratios (Table 4).

Correlations between different workforce metrics and health service characteristics were mostly statistically non-significant. Annual turnover rates, however, had a weak negative correlation with an indicator of staff supply (average number of nurses and AHPs actually working). The experienced nurse or AHP indicator had positive correlations of moderate strength with several indicators of health service size (community population size, average number of nurses and AHPs actually working and average number of FTE nurse and AHP positions on 2015 organisational chart) (Table 5).

\section{Discussion}

This landmark study is one of very few studies that measure turnover and retention from the perspective of a particular health service. Taking this perspective is important because it reflects what the experience of health professional continuity of care might be like from the viewpoint of consumers in a remote community. The study reveals extremely high annual turnover and poor retention for nurses and AHPs in remote NT health services. While combined nurse and AHP turnover and retention rates are less extreme when defined as either leaving remote services, they are nevertheless highly unstable and far higher than what has been reported in NT and in comparable contexts elsewhere [17, 18]. Sub-analysis of unpublished NTG DoH data by individual professional groups shows that the organisational turnover from NTG DoH was $34 \%$ for nurses $(32 \%-36 \%), 22 \%$ for AHPs $(13 \%-30 \%)$ and 33\% for all staff (32\%-34\%) between 2013 and 2015. This is consistent with our study which found that turnover rates were significantly higher for nurses compared to AHPs. While our study was not designed to explore the underlying reasons for differences in turnover of nurses compared to AHPs, it is likely that an important effect relates to many AHPs working in communities located on their traditional land and in which they have extended family. The study also confirms anecdotal reports that agency nurses provide a substantial proportion of primary care in NT remote communities, without whose services there would undoubtedly be significant gaps in the availability of primary care services.

These findings have important implications for remote health services more generally, their patients and for policymakers. Firstly, very high turnover rates mean that health services in remote communities will need to invest considerable resources to adequately prepare and orient new staff to the health service and community [22]. Of course, there is a trade-off between investing resources in orienting new staff and investing those resources directly in providing health services for the community, particularly in an under-resourced environment. Clearly, the shorter the period of time new staff intend to stay in a remote clinic, the more the balance shifts towards investing directly in providing health services and away from providing extensive orientation, since the return on investment in orienting new staff will be small for the most short-term staff. Nevertheless, it remains important that new staff are trained to provide appropriate and culturally safe care.

Secondly, lower turnover and higher stability rates amongst AHPs compared to nurses suggest that remote workforce stability may be better supported by greater career development and employment opportunities for local Aboriginal community members to become AHPs and nurses. Increased employment of Aboriginal local community members in a range of other positions, including administrative (community workers, alcohol and other drug workers, etc.) and logistic support roles (drivers, cleaners, gardeners) may similarly help provide improved overall health workforce stability and simultaneously improve accessibility, quality of care and cultural appropriateness of health care [27].

Thirdly, high staff turnover and low stability rates are also likely to result in the already limited funding available for remote health services being substantially less than 


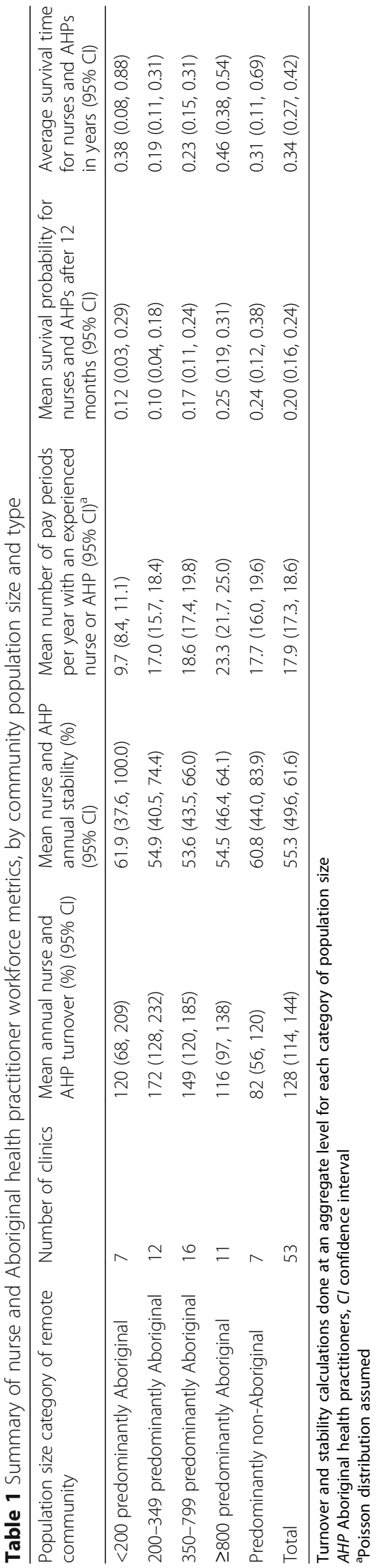




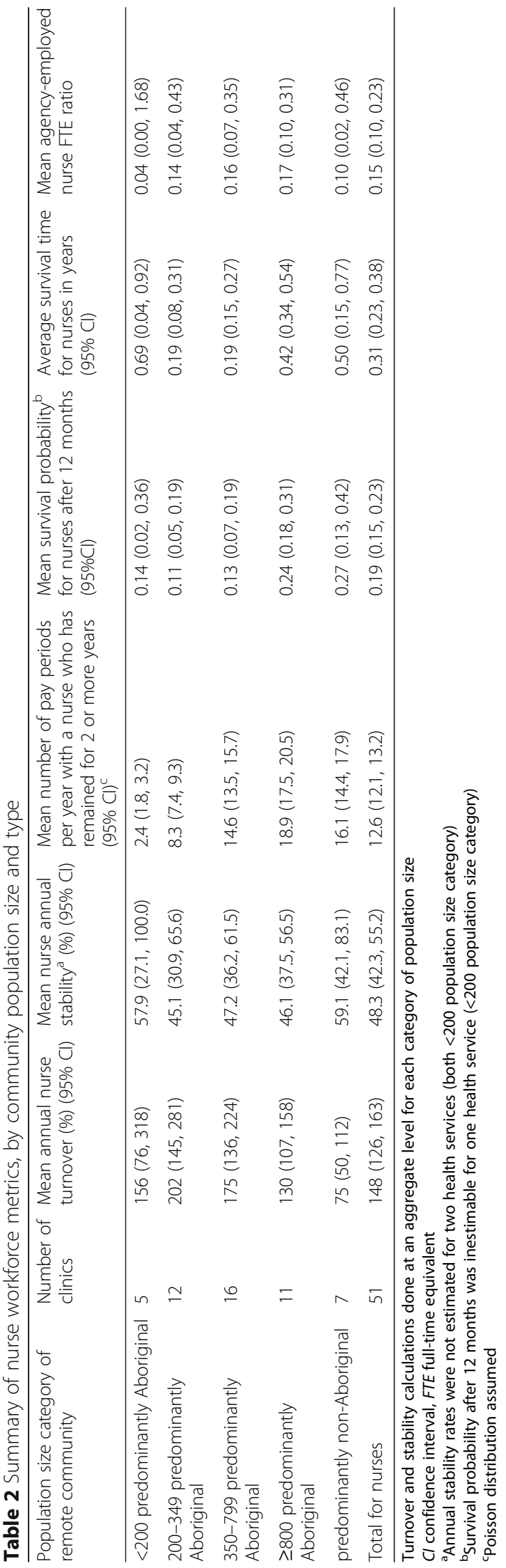




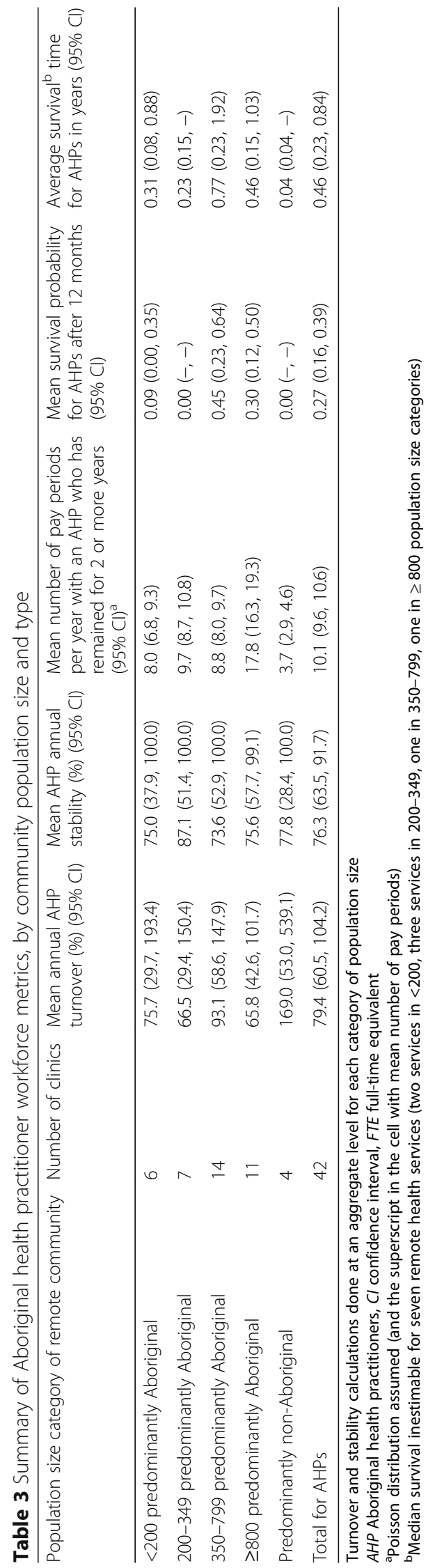




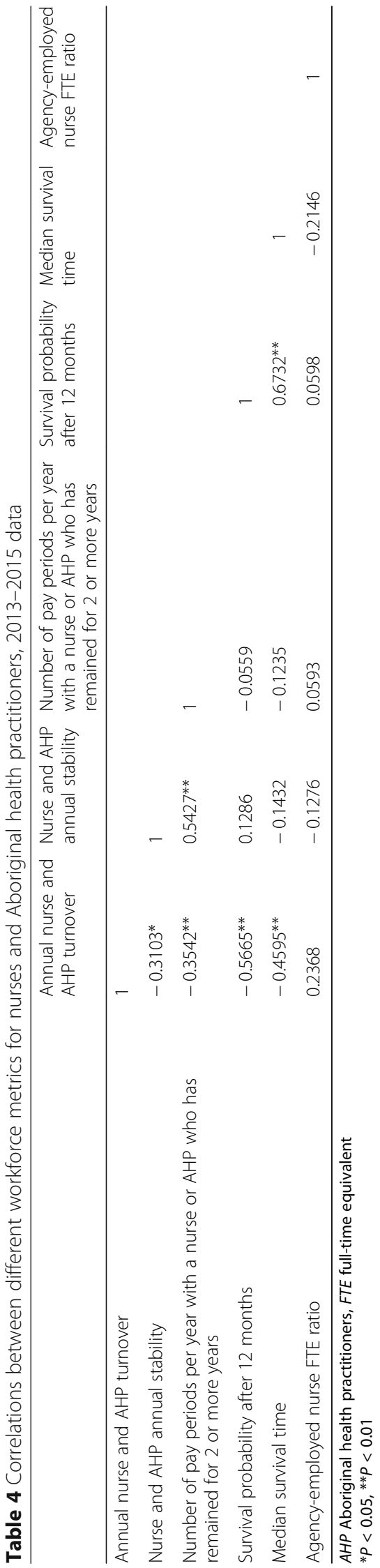


Table 5 Correlations between workforce metrics for nurses and Aboriginal health practitioners 2013-2015 and health service characteristics

\begin{tabular}{|c|c|c|c|c|c|c|}
\hline Health service characteristic & Annual turnover & $\begin{array}{l}\text { Stability after } \\
12 \text { months }\end{array}$ & $\begin{array}{l}2 \text { years + experienced } \\
\text { nurse or AHP }\end{array}$ & $\begin{array}{l}12 \text { month survival } \\
\text { probability }\end{array}$ & $\begin{array}{l}\text { Median } \\
\text { survival }\end{array}$ & $\begin{array}{l}\text { Agency-employed } \\
\text { nurse FTE ratio } \\
\end{array}$ \\
\hline Distance to the nearest hospital & 0.1071 & -0.1872 & -0.1074 & -0.0720 & -0.0499 & 0.2182 \\
\hline Distance to Darwin or Alice Springs & -0.0146 & -0.2303 & -0.0156 & 0.0073 & -0.0419 & 0.2378 \\
\hline Community population size & -0.2183 & -0.0587 & $0.3846^{* *}$ & 0.1080 & 0.1255 & 0.1757 \\
\hline $\begin{array}{l}\text { Average number of nurses and } \\
\text { AHPs actually working }\end{array}$ & $-0.2929^{*}$ & -0.0270 & $0.5163^{* *}$ & 0.0419 & 0.1232 & 0.0900 \\
\hline $\begin{array}{l}\text { Average number of FTE nurse and AHP } \\
\text { positions on } 2015 \text { organisational chart }\end{array}$ & -0.1799 & -0.1856 & $0.4076^{* *}$ & 0.0167 & 0.1575 & 0.0831 \\
\hline
\end{tabular}

${ }^{*} P<0.05 ; * * P<0.01$

AHP Aboriginal health practitioners, FTE full-time equivalent

would otherwise be available because of the excess costs of recruitment, agency fees and transport, orientation and induction, housing and other higher costs for new staff and for agency staff [27]. Extremely high turnover rates may also increase risks to staff safety as constantly changing staff may be associated with decreased awareness of occupational health safety hazards [28]. Vacancies associated with staff turnover may also exacerbate safety risks for remaining resident staff, as fewer than the optimal numbers of staff are available to deliver services. High turnover and poor retention, together with high use of short-term agency staff, are also likely to limit the ability of the health service to provide high-quality care and participate meaningfully in continuous quality improvement activities [27]. Lack of stable resident primary care providers is also likely to compromise the effectiveness of visiting specialist and allied health services, since primary care providers in remote communities have a key role to identify and prioritise who needs to be seen for what and subsequently to implement and monitor any required follow-up.

For patients, high use of agency staff by health services, in conjunction with low retention and high turnover of NTG DoH-employed staff, results in relational discontinuity with their primary care providers. This is particularly important for Aboriginal patients, especially those with more serious or chronic health problems, as it means that the time needed for them to feel culturally safe and begin trusting their primary care providers is not available. As a result, patients may be less likely to access the care they need in a timely way [29]. Further, it is more likely that they will experience health encounters where the primary care provider is not adequately prepared for working in a complex cross-cultural environment. Ultimately, the quality of care that they receive is likely to be lower and their health outcomes poorer.

Some of the workforce metrics that were calculated in this analysis have not previously been reported in the published, peer-reviewed literature to describe workforce turnover and retention patterns. In small, remote health services which may have only one or two key nurses or AHPs, the health service workforce can be highly unstable and switch between periods of relative staffing stability and periods of high use of short-term staff. This study developed a new metric to indicate the number of pay periods for which a health service had at least one nurse or AHP who had at least 2 years' clinical experience in that community. It is intended that each of the turnover or retention metrics used in this study, including the new metric, will be tested to assess their usefulness in predicting quality of primary care and potentially avoidable hospitalisations. While the usefulness of this metric is yet to be tested in other comparable contexts, our research nevertheless corroborates the use of multiple well-established workforce metrics, including annual turnover rates, annual stability rates and survival probabilities, to provide a comprehensive picture of patterns of workforce turnover and retention in remote health services. We found moderate to strongly significant correlations between annual turnover rates and other workforce metrics suggested by Russell et al. for use in rural health services [9]. Most workforce metrics, with the exception of experienced staff, were not significantly correlated with health service characteristics. This perhaps reflects that the 53 health services in the study were all at the extreme end of the spectrum of staff turnover and retention experienced in Australian health services and therefore unable to be differentiated according to community population size or distances to the nearest hospitals or to Darwin/ Alice Springs.

Given the substantial policy significance of these research findings, it is important to acknowledge several limitations of the data and analysis. Firstly, data on agency-employed nurses were not available at an individual level, could not be integrated with payroll data and were not recorded in a sufficiently accurate or detailed way to enable complete capture of all agency nurses at each remote health service. The turnover rates reported are therefore underestimates, since they exclude agency nurses paid directly by agencies. Similarly, stability rates 
may represent overestimates of the overall patterns. Anecdotal information from health service providers confirm these assertions. The financial expenditure for labour hire costs, used to derive agency-employed nurse FTE, however, are considered to be accurate and reliable and have been used in our research to provide a comprehensive overall picture of staffing patterns in remote communities.

Secondly, it was not possible to allocate staff on the NTG DoH payroll working in a supernumerary capacity to specific health services if the cost centre covered multiple remote services. However, these comprised only a small proportion of nursing and AHP staff. Similarly, we were unable to allocate all of the aggregated agency-employed nurse FTE data to specific remote health services, as some of the cost centres covered multiple remote services. Further, our definition of agency-employed nurse excludes those agency nurses paid directly by NTG DoH, and our analysis has not attempted to specifically identify agency nurses on NTG DoH casual or temporary contracts. Our overall reported agency-employed nurse FTE ratio of 0.15 is therefore likely to be a substantial underestimate of total NTG DoH use of agency nurses. One recent report quotes a figure of $42 \%$ of remote nursing positions filled by agency-employed and NTG DoH-employed agency nurses [22]. Anecdotal evidence from nurse coordinators also indicates that between a third and a half of remote NT nursing positions are currently filled by agency nurses.

Thirdly, in focussing our analysis on nurses and AHPs, we do not capture all clinical and non-clinical staff working at remote health services. Remote health services function with the support of resident administrative staff, Aboriginal community workers, alcohol and other drugs workers, Aboriginal mental health workers, cleaners, drivers, gardeners, receptionists, community liaison officers, healthy lifestyle educators and so on. A small number of remote communities also have resident doctors for whom workforce mobility information was not available. Further, remote health clinics are often supported by visiting outreach workers providing medical, nursing and allied health services across a range of areas including public health, continuous quality improvement, health promotion, preventable chronic disease coordination and across various health care specialties. This analysis, therefore, while focused on the nurse and AHP workforce who are resident in communities, does not capture the entire spectrum of health providers working in these communities.

Nonetheless, these limitations notwithstanding, the implications of the findings of this research for policymakers are profound. In the face of such high turnover, we need robust health service models that are adequately funded, competently managed and clinical protocol driven. It is also crucial that health workforce policies are developed that effectively stabilise the remote primary care workforce and optimise workforce turnover because the benefits of continuing heavy reliance on short-term nursing staff are offset, and at times entirely negated by, substantial downsides. Stabilising the remote workforce may require different workforce models to be utilised. For example, individuals may work 1 month on, 1 month off in remote communities in shared positions. Other possible solutions include emulating medical workforce training strategies with preferential selection of rural or remote students into nursing and AHP training courses, providing vocational training based in rural and remote settings, supporting students with remote scholarships and providing recruitment and retention incentives for working in remote locations once students graduate. Another strategy may be to eliminate barriers that remote dwelling Aboriginal Australians face when entering and remaining in the health workforce. These barriers include English literacy and numeracy levels, adequacy of remuneration for AHPs, and employment conditions such as lack of subsidised housing, each of which may act as a deterrent. In the face of geographical maldistribution of doctors, communitybased remote nurse practitioners may help to stabilise the workforce and improve access.

\section{Conclusions}

This research provides rigorous empirical evidence that in remote NT communities with NTG DoH health services, turnover of nurses and Aboriginal health practitioners is extremely high, stability rates are low and substantial use is made of agency nurse services. These staffing patterns are almost certainly contributing to sub-optimal continuity of care, compromised health outcomes, poorer levels of staff safety and higher costs. To effectively address these deficiencies, it is imperative that Territory and Federal Governments invest in implementing, adequately resourcing and evaluating staffing models which effectively stabilise the remote primary care workforce as a matter of priority. The results are also important for quantifying workforce patterns in a rural or remote area, a subject for which there has been substantial national and international interest but limited research.

\section{Abbreviations}

95\%Cl: 95\% confidence interval; AHP: Aboriginal health practitioner; AHW: Aboriginal health worker; DoH: Department of Health; FTE: Full-time equivalent; GAS: Government accounting system; IQR: Interquartile range; NT: Northern Territory; NTER: Northern Territory emergency response; NTG: Northern Territory Government; PIPS: Personnel information and payroll systems

\section{Acknowledgements}

We wish to thank Steve Kyriacou, who provided technical assistance in accessing and interpreting departmental personnel and financial data and Professor David Lyle for feedback we received on our manuscript during its 
drafting. We would also like to acknowledge and sincerely thank all staff working in the 53 remote NT communities, particularly the clinic managers.

\section{Funding}

This project was supported under Australian Research Council's Discovery Projects funding scheme (project number DP150102227).

\section{Availability of data and materials}

The datasets generated and analysed during the current study are not publicly available due to identifiability of remote primary care providers and the need to protect their privacy.

\section{Authors' contributions}

This research was conceived by JW, JH, SG, YZ and MJ. The study was planned and coordinated by JW, SG, DR, MR, YZ, MJ and JH. Contributors to the analysis and interpretation were DR, YZ, MJ, SG, MR and JW. All authors helped draft the manuscript and read and approved the final manuscript.

\section{Ethics approval and consent to participate}

Ethics approval was received from the Human Research Ethics Committee of the Northern Territory Department of Health and Menzies School of Health Research (2015-2363).

\section{Consent for publication}

Not applicable.

\section{Competing interests}

The authors declare that they have no competing interests.

\section{Publisher's Note}

Springer Nature remains neutral with regard to jurisdictional claims in published maps and institutional affiliations.

\section{Author details}

'Monash Rural Health, Monash University, PO Box 666, Bendigo, Victoria 3552, Australia. ${ }^{2}$ Department of Health, PO Box 40596, Darwin, NT 0800 Australia. ${ }^{3}$ Faculty of Human Sciences, Macquarie University, North Ryde, NSW 2109, Australia. ${ }^{4}$ Monash Rural Health, Monash University, PO Box 91 Strathdale, Victoria 3550, Australia. ${ }^{5}$ Flinders Northern Territory, School of Medicine, Flinders University, PO Box U362, Casuarina, NT 0815, Australia.

\section{Received: 16 February 2017 Accepted: 7 August 2017}

Published online: 15 August 2017

\section{References}

1. World Health Organization. The World Health Report 2006: working together for health. Geneva: WHO; 2006.

2. Sharma DC. India still struggles with rural doctor shortages. Lancet. 2015:386:2381-2.

3. Sommanustweechai A, Putthasri W, Nwe ML, Aung ST, Theint MM, Tangcharoensathien V, Wynn SS. Community health worker in hard-toreach rural areas of Myanmar: filling primary health care service gaps. Hum Resour Health. 2016;14:64.

4. Terschuren $\mathrm{C}$, Mensing $\mathrm{M}$, Mekel $\mathrm{OCL}$. Is telemonitoring an option against shortage of physicians in rural regions? attitude towards telemedical devices in the North Rhine-Westphalian health survey, Germany. BMC Health Serv Res. 2012;12:95

5. Dove N. Can international medical graduates help solve Canada's shortage of rural physicians? Canadian Journal of Rural Medicine. 2009;14:120.

6. Vujicic M, Shengelia B, Alfano M, Thu HB. Physician shortages in rural Vietnam: using a labor market approach to inform policy. Soc Sci Med. 2011;73:970-7.

7. Kippenbrock T, Lo W-J, Odell E, Buron B. The Southern states: NPs made an impact in rural and healthcare shortage areas. Journal of the American Association of Nurse Practitioners. 2015:27:707-13.

8. Mason J. Review of Australian government health workforce programs. Canberra: Australian Government Department of Health; 2013.

9. Russell DJ, Humphreys JS, Wakerman J. How best to measure health workforce turnover and retention: five key metrics. Aust Health Rev. 2012;36:290-5.
10. Waldman JD. Change your metrics: if you get what you measure, then measure what you want-retention. J Med Pract Manage. 2006:22:13-9.

11. Waldman JD. Measuring retention rather than turnover: a different and complementary HR calculus. Hum Resour Plan. 2004;27:6-9.

12. Dolea C, Stormont L, Braichet JM. Evaluated strategies to increase attraction and retention of health workers in remote and rural areas. Bull World Health Organ. 2010;88:379-85

13. Pathman DE, Konrad TR, Ricketts TC. The comparative retention of National Health Service Corps and other rural physicians. Results of a 9-year follow-up study. JAMA: Journal of the American Medical Association. 1992;268:1552-8.

14. Jones $C B$. The costs of nurse turnover, part 2: application of the nursing turnover cost calculation methodology. J Nurs Adm. 2005;35:41-9.

15. Nursing Solutions Inc. National healthcare retention \& RN staffing report, vol. 2016. East Petersburg, PA: NSI; 2016

16. Kosel KC, Olivo T: The business case for workforce stability. Irving, TX; VHA Inc.; 2002.

17. Garnett ST, Coe K, Golebiowska K, Walsh H, Zander KK, Guthridge S, Li S, Malyon R. Attracting and keeping nursing professionals in an environment of chronic labour shortage: a study of mobility among nurses and midwives in the Northern Territory of Australia. Darwin: Charles Darwin University Press; 2008.

18. Health Q. Ministerial taskforce: nursing recruitment and retention. Final report. Queensland Health: Brisbane; 1999

19. Boffa JD, Bell Al, Davies TE, Paterson J, Cooper DE. The Aboriginal Medical Services Alliance Northern Territory: engaging with the intervention to improve primary health care. Med J Aust. 2007;187:617-8.

20. Studdert L. Remote Area Health Corps: nurses making a contribution to primary health services in the NT. Australas Emerg Nurs J. 2010;13:142.

21. Busbridge MJ, Smith A. Fly in/fly out health workers: a barrier to quality in health care. Rural Remote Health. 2015;15:3339.

22. Northern Territory Government Department of Health. Remote area nurse safety: on-call after hours security. Darwin: NT Department of Health; 2016

23. Health Workforce Australia. Aboriginal and Torres Strait Islander Health Worker project. Adelaide: HWA; 2011.

24. Australian Institute of Health and Welfare. Aboriginal and Torres Strait Islander health practitioner workforce 2014. Canberra: AlHW; 2016

25. Australian Bureau of Statistics. Estimates of Aboriginal and Torres Strait Islander Australians, Jun 2011. Cat No. 3238.0.55.001. Canberra: ABS; 2013.

26. Northern Territory Government Department of Health. Indicator definition: full time equivalents v1.0. Darwin: NTG Department of Health; 2015.

27. Parliament of Australia. Report on the inquiry into nursing. The patient profession: time for action. Canberra: Commonwealth of Australia; 2002.

28. CRANAplus. Remote health workforce safety and security report: literature review, consultation and survey report. Cairns, Australia: CRANAplus; 2017.

29. Guthrie B, Saultz JW, Freeman GK, Haggerty JL. Continuity of care matters. BMJ. 2008:337:a867.

\section{Submit your next manuscript to BioMed Central} and we will help you at every step:

- We accept pre-submission inquiries

- Our selector tool helps you to find the most relevant journal

- We provide round the clock customer support

- Convenient online submission

- Thorough peer review

- Inclusion in PubMed and all major indexing services

- Maximum visibility for your research

Submit your manuscript at www.biomedcentral.com/submit 